\title{
DELIRIUM EM IDOSOS HOSPITALIZADOS NA CLÍNICA CIRÚRGICA NO
} PARANÁ

Gabriela Serighelli da Rosa; Universidade Estadual de Ponta Grossa; serighelligabriela@gmail.com

Emerson C. Souza Filho; Universidade Estadual De Ponta Grossa; emersonsouza23122000@gmail.com Jacy Aurelia Vieira de Sousa; Universidade Estadual de Ponta Grossa; jacy.sousa@gmail.com

\section{RESUMO}

Introdução: Delirium é definido como uma síndrome neurocomportamental causada pela insuficiência aguda e transitória da atividade cerebral. No transoperatório caracteriza-se por distração e outros distúrbios da função cerebral. Objetivo: Caracterizar idosos hospitalizados em clínica cirúrgica de um hospital do Paraná, quanto a características sociodemográficas, clínicas e ocorrência de Delirium. Métodos: Estudo observacional, retrospectivo, desenvolvido no setor da clínica cirúrgica de um hospital no Paraná. A população foi composta por pacientes com 60 anos ou mais internados de maio a agosto de 2019. Utilizou-se um instrumento com variáveis sociodemográficas e clínicas, a escala de Richmond Agitation-Sedation (RASS) e o Confusion Assessment Method (CAM). Resultados: A amostra foi composta por 31 idosos, com predomínio do sexo feminino (18; 58,06\%), com faixa etária de 70 a 79 anos $(13 ; 41,94 \%)$, com escolaridade baixa (19; $61,29 \%)$, casados $(12 ; 38,71 \%)$ e aposentados $(22 ; 70,97 \%)$. Predominou as cirurgias ortopédicas (10; 32,26\%) e idosos com presença de hipertensão arterial sistêmica (HAS) (21; 67,74\%). Quanto à CAM, apenas $02(07 ; 14 \%)$ idosos do sexo masculino apresentaram critérios para a classificação de Delirium. Quanto à RASS, 26 (82; 14\%) idosos apresentavam-se em estado alerta/calmo, 03 (10; $71 \%)$ apresentavam-se sonolentos e $02(07 ; 14 \%)$ apresentavam-se inquietos. Conclusão: Conclui-se que os dados sociodemográficos e clínicos reconhecidos em idosos no transoperatório, como a predominância do sexo feminino, com baixa escolaridade, estado civil casados e aposentados. A morbidade com maior prevalência foi a HAS e as cirurgias mais realizadas foram as ortopédicas. Mesmo com uma amostra pequena observou-se a presença de delirium.

Palavras-chave: Delirium; Saúde do idoso; Enfermagem geriátrica.

Agradecimentos: Agradeço à Fundação Araucária pelo financiamento da bolsa e a UEPG pelas oportunidades. Agradeço a minha orientadora Jacy Aurelia Vieira de Sousa por toda a sua paciência e ensinamentos. Agradeço aos meus colegas por toda ajuda que tive na realização deste trabalho, em especial ao Emerson C. Souza Filho. 